\title{
How to Enhance Digital Literacy Skills among Information Sciences Students
}

\author{
Siriwatchana Kaeophanuek, Jaitip Na-Songkhla, and Prachyanun Nilsook
}

\begin{abstract}
This research aims to study Thai university library and information sciences instructors' and students' opinions on teaching and learning environments for the development of digital literacy skills. The research tools included digital literacy self-assessment and in-depth interviews. The findings indicate that 400 students from across Thailand considered their abilities for digital tools usage good and that they considered their information and digital transformation skills to be at an intermediate level. Interviews with the instructors revealed information about teaching environments, problems and obstacles, and the interviews indicated alternative methods for Information Sciences students' digital literacy development.
\end{abstract}

Index Terms-Digital literacy, instructional design, information sciences, higher education.

\section{INTRODUCTION}

It is generally known that digital technologies play an important role in the digital age. Hence, there is a need to close the gap in digital device accessibility and expand opportunities to access technology in order to create equality. However, creates a significant problem: students' failure to understand how to use such technology in the learning process [1]. Although students are capable of accessing technology, they are not able to use it efficiently, especially when it comes to the learning process [2]. Even though instructors attempt to support social media usage in order to engage students' attention [3], they are not able to integrate this into students' continuous learning process. Indeed, students rely on technology usage yet they lack critical evaluation, selection and usage knowledge, as well as academic skills [1], [4], [5]. This includes supporting the critical usage of technology in order to efficiently exceed capacities in various aspects.

Consequently, providing advice on using technology for learning purposes has become a significant issue for the digital learning environment [6], especially for information scientists who play a role in digital content and media production. In accordance with the coming of the digital age, information sources and general knowledge have been transformed into digital formats and such resources have dramatically increased in number [7]. The capacity to present and produce content within the digital environment is considered a vital qualification for twenty-first-century information scientists. They need to be capable of adapting

Manuscript received June 25, 2017; revised August 17, 2017.

S. Kaeophanuek and J. Na-Songkhla are with the Faculty of Education, Chulalongkorn University, Bangkok, Thailand (e-mail: ksirivaj@gmail.com, jaitip.n@chula.ac.th).

P. Nilsook is with the Faculty of Technical Education, King Mongkut's University of Technology North Bangkok (KMUTNB), Bangkok, Thailand (e-mail: prachyanunn@kmutnb.ac.th). their roles - transforming from readers into quality writers in the digital world and from customers to information generators [8]-[10]. Information, media or computer literacy, therefore, are not sufficient capabilities by themselves for information scientists in the digital age. Information scientists need to be capable of critical thinking and interpretation, and they also need to be able to use digital tools in order to generate digital content and information in several forms. Digital literacy development is regarded as another challenging role for universities that offer library and information sciences courses for information scientists and developers in the twenty-first century [4], [8], [9], [11].

The purpose of this research was to study the opinions of instructors and undergraduate information sciences students at Thai universities in order to analyse students' digital literacy competence and identify the barriers that stop them from attaining these necessary skills. From this research, it is expected that solutions can be proposed for both alternative methods of instructional design and related skills support, as well as methods for enhancing digital literacy competence.

The research questions were divided into two aspects:

RQ1: What level are information sciences students' digital literacy skills?

RQ2: What should the environment be like for teaching digital literary competence?

\section{LITERATURE REVIEW}

\section{A. Digital Literacy}

The debate surrounding the definition of digital literacy started as early as the 1990s. Digital literacy has been defined in various ways since the term was first introduced by [12]. In 1997, this concept appeared in a book entitled Digital Literacy, in which the author defined digital literacy as the ability to comprehend and apply various forms of information science from several sources in order to present information on the computer. Later, in 2005, [13] suggested a more complete definition. He defined digital literacy as the individual realisation, attitude and capacity of digital tools usage in order to access, manage, integrate, analyse and synthesise digital information sources. This includes generating new knowledge and producing many forms of digital media in order to communicate, create and reflect the concepts within other daily life situations. [14] notes that digital literacy consists of three dimensions: technical, cognitive and sociological skills. These are used to solve problems within the environment of a digital society.

Furthermore, a number of scholars define digital literacy as a circumstance of technological development. Individuals with digital literacy skills must be able to use technology as the digital age's information management tools [15] in terms 
of management, evaluation and communication, and they must possess a fundamental knowledge of the laws and ethical issues concerning information access. In other words, digital literary could encompass the application of technology for a presentation or problem solving, co-operating and knowledge sharing, as well as being aware of individual responsibilities and the individual rights of oneself and others [5].

Consequently, acquiring digital literacy education means the ability to access various information sources, the practical capacity to use digital tools for information sources management and the ability to generate and share different media, as well as the ability to efficiently present and communicate using the proper processes and tools [16], [17]. In addition, [18] indicates that digital literacy is the situation in which a person is encouraged by society to use his/her skills, capacities and strategies to present and comprehend the concept of various kinds of media, as well as efficiently apply digital tools and develop ideas and concepts.

This research is underpinned by the digital literacy framework of [13] and synthesised digital competences from review literatures. The ideas can be summarised with a synthesis, as shown in Table I [13], [14], [19]-[25].

As shown in Table I, the researcher selected related information and divided digital literacy skills into three skill indicator categories as follows:

1) Information skills: the fundamental concepts of information management and the techniques and methods related to information management. This category is comprised of problem definition, issue searches, the methods and strategies for accessing analysis, synthesis, content systematisation, evaluation, interpretation and information application for solving problems or working properly.

2) Digital tools usage: the skills and competencies required to learn and use various software applications, digital tools usage for daily life convenience and meeting goals, an ability to manage and solve basic computer problems, communication skills, an ability to manage personal information on networks and the application of technology for co-working and ethics. Digital literacy requires the technical ability to operate digital devices, as well as a variety of cognitive skills to execute tasks in digital environments.

3) Digital transformation: the consolidation of information using evaluation skills with the aim of generating, improving, designing, producing and presenting new forms of information, creating new knowledge, creatively producing digital innovation by co-learning, reflecting on what could be improved and publishing work while understanding internet information copyright law.

Having studied the literature review, the researcher summarised the definition of digital literacy as an individual's ability to properly use technology as a tool in order to facilitate information management, as well as to create and present new forms of information, to solve problems and to apply digital literacy in daily life concerning individual responsibilities and rights for oneself and for others [26]. Furthermore, during the literature review, the researcher found that there is one main composition for digital literacy development that is regarded as a significant issue: cognitive skills. According to every composition of digital literacy development, students have to critically think, evaluate, decide and properly select information, which takes into account higher order thinking skills and this fits into a twenty-first-century skills perspective [18], [27], [28]. This also encompasses attitudes and perspectives concerning the ethical use of information. This is one of the significant compositions of appropriate behaviours for information specialist in terms of communication and digital information publishing, especially for the role of information producers, as shown in Fig. 1.

\begin{tabular}{|c|c|c|c|c|c|c|c|c|c|}
\hline Skills & {$[13]$} & [14] & [19] & [20] & [21] & [22] & [23] & [24] & [25] \\
\hline $\begin{array}{l}\text { Computer } \\
\text { skills }\end{array}$ & $\checkmark$ & $\checkmark$ & $\checkmark$ & $\checkmark$ & $\checkmark$ & $\checkmark$ & $\checkmark$ & $\checkmark$ & \\
\hline Definition & $\checkmark$ & $\checkmark$ & & $\checkmark$ & $\checkmark$ & $\checkmark$ & $\checkmark$ & $\checkmark$ & $\checkmark$ \\
\hline Access & $\checkmark$ & $\checkmark$ & $\checkmark$ & $\checkmark$ & $\checkmark$ & $\checkmark$ & $\checkmark$ & $\checkmark$ & $\checkmark$ \\
\hline $\begin{array}{l}\text { Analysis } \\
\text { /synthesis }\end{array}$ & $\checkmark$ & $\checkmark$ & $\checkmark$ & $\checkmark$ & $\checkmark$ & & $\checkmark$ & $\checkmark$ & $\checkmark$ \\
\hline Evaluation & $\checkmark$ & $\checkmark$ & $\checkmark$ & $\checkmark$ & $\checkmark$ & $\checkmark$ & $\checkmark$ & $\checkmark$ & $\checkmark$ \\
\hline Interpretation & $\checkmark$ & & $\checkmark$ & $\checkmark$ & $\checkmark$ & $\checkmark$ & & $\checkmark$ & \\
\hline Creation & $\checkmark$ & $\checkmark$ & $\checkmark$ & $\checkmark$ & $\checkmark$ & & $\checkmark$ & $\checkmark$ & $\checkmark$ \\
\hline Usage & & & & $\checkmark$ & & & & $\checkmark$ & $\checkmark$ \\
\hline Communication & $\checkmark$ & $\checkmark$ & $\checkmark$ & $\checkmark$ & & & $\checkmark$ & & \\
\hline Collaboration & & & & & $\checkmark$ & & & & $\checkmark$ \\
\hline Dissemination & $\checkmark$ & $\checkmark$ & & & $\checkmark$ & & & & $\checkmark$ \\
\hline Reflection & $\checkmark$ & & & & $\checkmark$ & & & & $\checkmark$ \\
\hline Ethical issues & & & $\checkmark$ & & & $\checkmark$ & & & \\
\hline
\end{tabular}

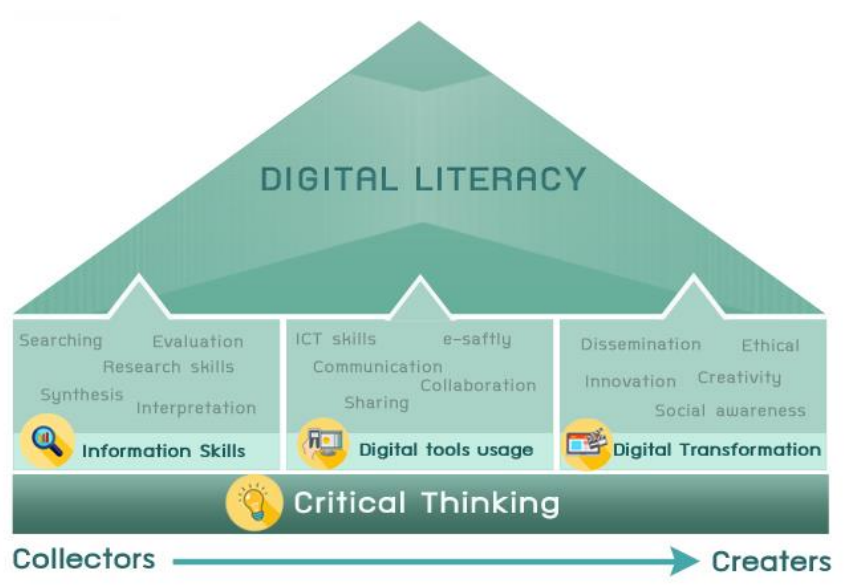

Fig. 1. Elements of digital literacy competence for information specialist.

\section{Methodology}

\section{A. Participants}

The sample groups for this study were divided into two groups: undergraduate students at government universities and instructors. The details are summarised below.

1) Students for the survey consisted of Thai university juniors enrolled at 12 universities in the fields of library and information sciences, information studies and information management. A simple random sample was produced by the $\mathrm{G}^{*}$ power calculating program to calculate the size of a sample group consisting of 400 
participants. Then, cluster sampling was completed, which were selected in and outside the Bangkok metropolitan area. Three universities were selected for each region by drawing lots. The process was considered an opportunity for equal rights.

2) The group of instructors included library and information sciences and information management instructors working during the first semester of 2016. Purposive sampling was completed using the following criteria: first instructors needed to have at least 10 years experience in the field of instruction; and, they needed to work for well-recognised institutions in the professional field. Instructors from five universities were selected: Konkhean University; Chulalongkorn University; Srinakharinwirot University; Walailak University; and Nakhon Si Thammarat Rajabhat University.

\section{B. Instruments}

This study was based on primary data gathered using both quantitative and qualitative methods, including a questionnaire and interviews.

1) Questionnaires about digital literacy competence evaluation were given to students. The questionnaire consisted of two parts. The first related to respondents' use of online service tools. The second part asked respondents to evaluate their self-perception of three aspects of digital literacy: information skills, digital tools usage and digital transformation. The measurement instrument was prepared from the literature and previous research and content validity (Content Validity Index: CVI) by using Lynn's index [29]. Five experts in the field of digital literacy, critical thinking and evaluation evaluated the questionnaire's linguistic accuracy. The standard content validity was estimated as 0.88 (S-CVI/Ave). The total individual content validity index (I-CVI) was higher than 0.67 and was considered acceptable [30], [31]. SPSS software was used to analyse the data and present the results of the study.

2) Instructors were interviewed about their perceptions of teacher librarians, who play a significant role in developing digital literacy skills by integrating digital technologies into student learning through explicit instruction, as well as obstacles to increasing digital literacy and new ways to encourage digital literacy. The research data was summarised by content analysis.

\section{RESULTS}

The results answered the two research questions. RQ1: What level are information sciences students' digital literacy skills; RQ2: What should the environment be like for teaching digital literary competence?

\section{A. Information Sciences Students' Digital Literacy}

The results of the questionnaires about the information sciences students' evaluation of their digital learning capacity are as follows:

\section{1) Online services}

The researcher categorised online service tools according to their purpose of use. The categories were divided into four groups: communication; daily life; learning; and production.
Considering the online service tools used by the respondents, it was found that the tools were mostly used for communication. Almost everyone used the tools to communicate with their friends on social media, such as Facebook, Twitter and Line. Of the participants, 357 also used online tools to search for information. Other purposes included sharing photos and videos and co-working with others, such as generating documents, collecting data or co-reporting. The least popular purposes were digital storytelling via digital medias; only 29 participants did this, as shown in Fig. 2. According to the research [32]-[36], it has been found that most students have the fundamental skills and capacity for properly using digital tools for communication and daily life actions.

\section{2) Digital literacy evaluation}

The results of the students' evaluations of self-perception concerning digital literary were divided into three aspects: information skills, digital tools usage and digital transformation. The data is presented as follows: The data analysis for this can be seen in Tables II-IV.

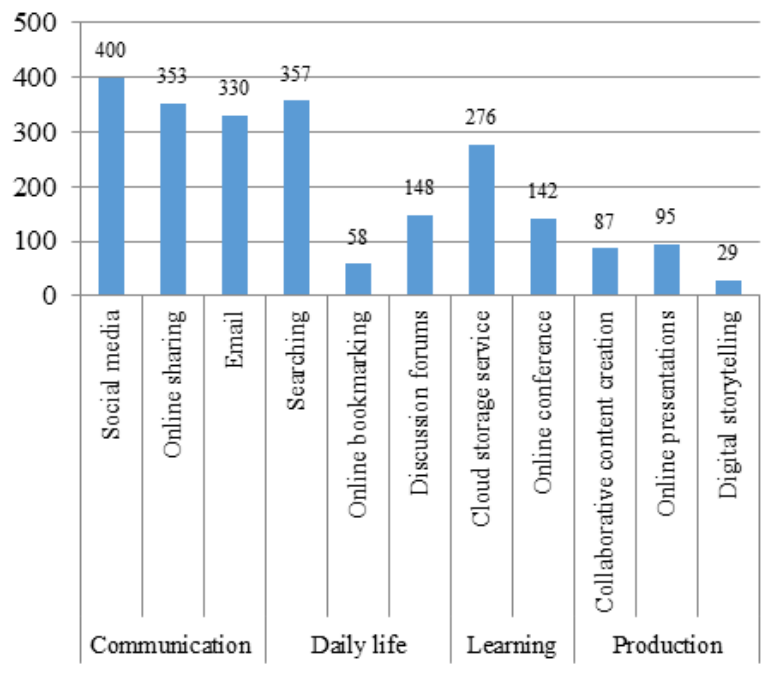

Fig. 2. Learning objectives using online service tools.

1) Information skills: a fundamental concept of digital information management and the techniques and methods related to information management. According to Table II, this study found that undergraduate information sciences students evaluated their information skills as being at an intermediate level (total mean 3.45). Most of the respondents were capable of sharing files on the internet $(\bar{x} 3.67)$ and many said that they examined the accuracy of information before using it ( $\bar{x} 3.62)$. The least understood information management technique was the application of Metadata ( $\bar{x} 3.16)$. In accordance with the data, it can be summarised that most of the students knew how to use social media properly. However, when they had to use their advanced skills to distinguish, categorise, integrate and apply information, they were not confident; therefore, the mean decreased.

2) Digital tools usage: a focus on the skills and abilities needed to use computer programs and applications, and the use of digital tools as a facility to solve problems in career and everyday life to achieve one's aims. An analysis of the information in Table III reveals that the 
undergraduate library and information science students' overall skills in digital tool usage were high (total mean 3.58). Most of the students were capable of using technologies to facilitate communication with other people $(\bar{x} 3.90)$ and they usually adapted technology to their everyday life ( $\bar{x} 3.83)$. The students displayed the lowest level of skill in fixing technical problems on computer systems $(\bar{x} 3.08)$.

TABLE II: INFORMATION SKILLS TABLE

\begin{tabular}{lccc}
\multicolumn{1}{c}{ Information skills } & Mean & SD & Meaning \\
\hline 1. Able to share files on the internet & $\mathbf{3 . 6 7}$ & $\mathbf{1 . 0 0}$ & High \\
2. Always examine the accuracy of & $\mathbf{3 . 6 2}$ & $\mathbf{0 . 9 1}$ & High \\
information before using & & &
\end{tabular}

3. Always evaluate data before sharing it $\quad 3.57 \quad 0.85 \quad$ High

on the internet

4. Consider consequences before giving $\quad 3.54 \quad 0.94 \quad$ High

opinions on social media

5. Evaluate the reliability of information $\quad 3.51 \quad 0.91 \quad$ Intermediate

sources before application

6. Able to define keyword in order to

search for expected information

7. Select appropriate data for solving

problems

8. Indicate frameworks in order to make

the search more efficient

9. Define information sources that match

expected information

10. Able to distinguish facts and

opinions

11. Able to analyse and synthesise

information gathered from various

sources

12. Able to categorise related

information

13. Able to integrate knowledge in order

to create new knowledge

14. Understand information

management by applying Metadata

Total mean

$3.48 \quad 0.85 \quad$ Intermediate

$3.48 \quad 0.84 \quad$ Intermediate

$3.44 \quad 0.84 \quad$ Intermediate

$3.44 \quad 0.84 \quad$ Intermediate

$3.44 \quad 0.93 \quad$ Intermediate

$3.36 \quad 0.85 \quad$ Intermediate

$3.35 \quad 0.80 \quad$ Intermediate

$3.28 \quad 0.88 \quad$ Intermediate

$3.16 \quad 0.98 \quad$ Intermediate

$3.45 \quad 0.89 \quad$ Intermediate

TABLE III: SKILLS IN DIGITAL TOOLS USAGE

\begin{tabular}{cccc}
\multicolumn{4}{c}{ TABLE III: SKILLS IN DIGITAL TOOLS USAGE } \\
\hline Skills in digital tools usage & Mean & SD & Meaning \\
\hline 1. Use social media as the usual & $\mathbf{3 . 9 0}$ & $\mathbf{1 . 0 0}$ & High
\end{tabular}

medium to communicate with

other people

2. Always adapt technology to

everyday life

3. Capable of selecting an optimal

social medium to communicate in

different situations

4. Concern about other people's

privacy when communicating

through social media

5. Aware of the advantages,

disadvantages and impact of using

the internet

6. Understand ethics in using the

internet and cyber bullying

7. Well-adjusted in learning new

technologies

8. Find tools and applications in

order to support everyday life

9. Aware of the methods used to

protect personal data on the internet

10. Able to organise collected data

on a personal computer

11. Able to self-teach in order to use applied programs

12. Able to self-teach in order to

study a special function of different

programs

\begin{tabular}{cccc}
\hline Skills in digital tools usage & Mean & SD & Meaning \\
\hline $\begin{array}{c}\text { 13. Able to fix technical problems } \\
\text { on a computer system } \\
\text { Total mean }\end{array}$ & 3.08 & 0.93 & Intermediate \\
\hline & 3.58 & 0.91 & High \\
\hline
\end{tabular}

3) Digital transformation: skills in information processing include improving, designing and creating content and projects, experimenting with new forms of data presentation, producing new knowledge, inventing digital innovations based on collaborative learning, reflecting on, developing and improving work and publishing work in accordance with copyright laws.

TABLE IV: SKILLS IN DIGITAL TRANSFORMATION

\begin{tabular}{|c|c|c|c|}
\hline Skills in digital transformation & Mean & SD & Meaning \\
\hline $\begin{array}{l}\text { 1. Aware when using others' work } \\
\text { without owners' permission }\end{array}$ & 3.77 & 1.03 & High \\
\hline 2. Understand plagiarism & 3.64 & 0.97 & High \\
\hline $\begin{array}{l}\text { 3. Create video media to use in a } \\
\text { presentation }\end{array}$ & 3.49 & 0.94 & Intermediate \\
\hline $\begin{array}{l}\text { 4. Aware that the videos they have } \\
\text { designed are copyrighted }\end{array}$ & 3.45 & 1.01 & Intermediate \\
\hline $\begin{array}{l}\text { 5. Able to share works designed by } \\
\text { each other with their friends on the } \\
\text { internet }\end{array}$ & 3.44 & 1 & Intermediate \\
\hline $\begin{array}{l}\text { 6. Understand the Creative } \\
\text { Commons concerning their } \\
\text { published works on the internet }\end{array}$ & 3.4 & 0.96 & Intermediate \\
\hline $\begin{array}{l}\text { 7. Able to create new content with } \\
\text { the tools on the internet }\end{array}$ & 3.31 & 0.91 & Intermediate \\
\hline $\begin{array}{l}\text { 8. Capable of transforming forms of } \\
\text { information in order to serve } \\
\text { different purposes }\end{array}$ & 3.22 & 0.87 & Intermediate \\
\hline $\begin{array}{l}\text { 9. Understand how to paraphrase in } \\
\text { academic writing }\end{array}$ & 3.14 & 0.84 & Intermediate \\
\hline $\begin{array}{l}\text { 10. Able to create new content by } \\
\text { themselves and avoid plagiarism }\end{array}$ & 3.13 & 0.89 & Intermediate \\
\hline Total mean & 3.40 & 0.94 & Intermediate \\
\hline
\end{tabular}

Analysis of the information shown in Table IV reveals that the undergraduate students in library and information science had intermediate-level overall skills in digital transformation (total mean 3.40). Most of the students understood that they should not use other people's work without the owners' permission $(\bar{x} 3.77)$ and they understood plagiarism $(\bar{x} 3.64)$. The students' ability to create their own work and avoid plagiarism was at the lowest level $(\bar{x} 3.13)$. This information demonstrates that the students understood copyright infringement, but lacked the skills to create new content on their own.

In conclusion, the students evaluated their digital learning skills in digital tools usage as being at a high level ( $\bar{x} 3.58)$, followed by information skills and digital transformation skills, which they evaluated as being, overall, at an intermediate level ( $\bar{x} 3.45$ and $\bar{x} 3.40$, respectively) as shown in Fig. 3.

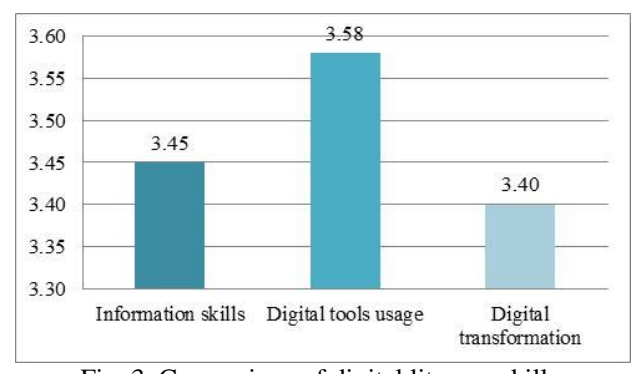

Fig. 3. Comparison of digital literacy skills. 


\section{B. Context Learning to Promote Digital Literacy}

The in-depth interviews focused on the three following topics: teaching environment, obstacles in instructional design and methods to develop digital literacy skills in undergraduate library and information science students. The interviews with instructors demonstrated that the methods used to develop digital literacy in information science students can be developed as follows. First, universities should set clear policies and provide the appropriate learning environment to facilitate the use of technology to support context learning, such as building infrastructural systems and encouraging the practical and progressive use of e-learning in every subject. Second, curricula should include content for skills that promote digital literacy by integrating such content into each subject, since the study found that promoting digital literacy cannot be achieved by only attending a workshop; instead, it must be studied in a lesson. Third, instructional design has to be a form of student-centred learning. Students should be encouraged to practise and fix problems by themselves with technology as a facility for instructional management. Every step should include the development of students' thinking and should focus on assessment by making students develop their thoughts by using the questioning strategy. Evaluation can help instructors learn about students' attitudes and behaviours when using social media. The questions to ask in class should be related to real situations or instructors should provide case studies that prompt students to think critically, ask questions and discuss their answers in class. Most students are aware of what they should do, but they have a difficulty enacting it in everyday life. Therefore, this is the challenging part in evaluating digital literacy. Finally, students should be inspired that an information specialist is a crucial role in the twenty-first century. Apart from gaining knowledge about information and technology management, students can do more than collecting data because they have the ability to create new knowledge or products [37]-[39]. According to [40], in order for students to develop their digital literacy, they have to understand the process of work creation via digital media, especially because information scientists nowadays not only present data but also create and edit data as content creators. They have to transform data into a form of digital information and develop methods for collecting and accessing information to make the process simple and convenient [41], [42].

\section{CONCLUSION}

The role of information specialist has changed and now includes digital content creation, something that has developed in many ways through our role as collectors, disseminators and preservers of information resources and the resultant opportunities for providing wider access through digitisation [43]. Thus, information sciences students should be taught the skills and knowledge necessary to manage digital creation projects. This study revealed that to develop an information specialist's digital literacy, s/he has to practise three skills: information management skills, digital tools usage and the creation of new content and the consolidation of information. The three skills are based on the process of developing cognitive skills, which have to be integrated into every step of the developmental process. This finding is in accordance with [44]. From the qualitative information collected in this study, the methods for creating effective teaching and learning environments for promoting digital literacy require that universities construct clear policies in order to support the fundamental structure of technology usage. The structure of technology will correspond to the curriculum and the content in each subject is adjusted by integrating digital literacy skills into related subjects [45] Moreover, instructors have to adopt optimal techniques, teaching methods and evaluations that encourage students to develop their thinking process, to question, discuss and debate and create projects using proper digital tools. In addition, instructors may encourage students to become aware of the important role of an information specialist as a digital content creator in the present moment and they could alert them to the fact that they can take on more moral responsibility as information intermediaries.

Further research is needed to explore how to design learning environments to improve learners' digital literacy in promoting students' skills in using digital tools to design and develop new forms of information science. The instructional design focuses on the critical thinking process and on students' skills in both developing an idea and creating an invention from their ideas. Students will be expert learners and will be able to solve problems creatively.

\section{REFERENCES}

[1] A. Littlejohn, H. Beetham, and L. McGill, "Learning at the digital frontier: A review of digital literacies in theory and practice," Journal of Computer Assisted Learning, vol. 28, pp. 547-556, 2012.

[2] T. Shopova, "Digital literacy of students and its improvement at the university," Journal on Efficiency and Responsibility in Education and Science, vol. 7, pp. 26-32, 2014.

[3] L. Smolin and K. Lawless, "Becoming literate in the technological age," Reading Teacher, vol. 56, pp. 570-573, 2003.

[4] P. Berger, "Blogging: A tool for information fluency," Educators Spotlight Digest, vol. 1, 2006.

[5] R. Sharpe. (2010). Conceptualizing differences in learners' experiences of e-learning: A review of contextual models. [Online]. Available: https://www.heacademy.ac.uk

[6] A. Margaryan, A. Littlejohn, and G. Vojt, "Are digital natives amyth or reality? university students'use of digital technologies," Computers \& Education, vol. 56, pp. 429-440, 2011.

[7] American Library Association. (2013). Digital literacy, libraries, and public policy: Report of the office for information technology policy's digital literacy task force. [Online]. Available: http://www.districtdispatch.org/wpcontent/uploads/2013/01/2012_OI TP_digilitreport_1_22_13.pdf

[8] I. McShane, "Public libraries, digital literacy and participatory culture," Discourse: Studies in the Cultural Politics of Education, vol. 32, pp. 383-397, January 2011.

[9] J. Hartley, The Uses of Digital Literacy, 1st ed. St Lucia, Australia: University of Queensland Press, 2009, p.17

[10] K. Czarnecki, "How digital storytelling builds 21st century skills," Library Technology Reports, vol. October, pp. 15-19, 2009.

[11] T. K. Huwe, "From librarian to digital communicator: following the media to new organizational roles," Information professional transformations, vol. 30, pp. 21-26, September/October 2006.

[12] P. Gilster, Digital Literacy. New York: Wiley, 1997, pp. 1-2

[13] A. Martin, "A European framework for digital literacy," Digital Kompetanse, vol. 2, pp. 151-161, 2006.

[14] Y. Eshet-Alkalai, "Digital literacy: A conceptual framework for survival skills in the digital era," Journal of Educational Multimedia and Hypermedia vol. 13, pp. 93-106, 2004.

[15] F. Jun and J. Pow, "Fostering digital literacy through web-based collaborative inquiry learning--a case study," Journal of Information Technology Education, vol. 10, p. IIP, January 2011.

[16] C. Hague. (2010). It's not chalk and talk anymore": school approaches to developing students' digital literacy. [Online]. Available: http://www.nfer.ac.uk/publications/FUTL09/FUTL09.pdf 
[17] J. P. Gee, "The old and the new in the new digital literacies," The Educational Forum, vol. 76, pp. 418-420, September 2012.

[18] D. O'Brien and C. Scharber, "Digital literacies go to school: Potholes and possibilities," Journal of Adolescent \& Adult Literacy, vol. 52, pp. 66-68, 2008.

[19] D. Bawden, "Origins and concepts of digital literacy," Digital Literacies: Concepts, Policies and Practices, New York: Peter Lang Publishing, 2008, pp. 17-32.

[20] Kempster. (2008). California ICT digital literacy assessments and curriculum framework. [Online]. Available: http://www.ictliteracy.info/rf.pdf/California\%20ICT\%20Assessments $\% 20$ and $\% 20$ Curriculum\%20Framework.pdf

[21] A. Cartelli, "Frameworks for digital competence assessment: proposals, instruments, and evaluation," in Proc. Informing Science \& IT Education Conference (InSITE), pp. 561-574, 2010.

[22] A. Calvani, A. Fini, and M. Ranieri, "Digital competence in k-12. theoretical models, assessment tools and empirical research," Analisi: Quaderns de Communicacio i Cultura, vol. 40, pp. 157-171, 2010

[23] W. Ng, "Digital literacy: The overarching element for successful technology integration," New Digital Technology in Education, Springer International Publishing, 2015, pp. 125-145.

[24] J. Pow and J. Fu, "Developing digital literacy through collaborative inquiry learning in the web 2.0 environment - An exploration of implementing strategy," Journal of Information Technology Education, vol. 11, pp. 287-299, 2012.

[25] R. Hobbs, "Empowering learners with digital and media literacy," Knowledge Quest, vol. 39, pp. 12-17, 2011.

[26] A. Martin and J. Grudziecki, "DigEuLit: Concepts and tools for digital literacy development," ITALICS: Innovations in Teaching \& Learning in Information \& Computer Sciences, vol. 5, pp. 246-264, 2006.

[27] A. Ferrari, Y. Punie, and C. Redecker, "Understanding digital competence in the 21st century: an analysis of current frameworks," in Proc. the 7th European conference on Technology Enhanced Learning, Germany, 2012.

[28] Y. Eshet, "Thinking in the digital era: A revised model for digital literacy," Issues in Informing Science \& Information Technology, vol. 9, pp. 267-276, 2012.

[29] M. R. Lynn, "Determination and quantification of content validity," Nursing Research, vol. 35, p. 382-385, 1986.

[30] L. Eyal, "Digital assessment literacy - The core role of the teacher in a digital environment," Journal of Educational Technology \& Society, vol. 15, pp. 37-49, April 2012.

[31] S. Covello. (2010). A review of digital literacy assessment instruments. [Online].

Available: http://www.apescience.com/id/fulltext/research-on-digital-literacy-ass essment-instruments

[32] R. Goodfellow, "Literacy, literacies and the digital in higher education," Teaching in Higher Education, vol. 16, pp. 131-144, February 2011.

[33] M. Hoechsmann and H. DeWaard. (2015). Mapping digital literacy policy and practice in the canadian education landscape. [Online] Available:

http://mediasmarts.ca/sites/mediasmarts/files/publication-report/full/m apping-digital-literacy.pdf

[34] P. Nilsook and P. Wannapiroon, "International distance consulting via web conferencing," International Journal of Emerging Technologies in Learning, vol. 9, no 4, pp. 60-64, 2014.

[35] J. Na-songkhla, "An effect of interactive media in a social awareness ubiquitous learning community," in Proc. International Conference on Lifelong Learning, Kualalumpur, Malaysia, 2011, pp. 1-24.

[36] N. Ozdamar-Keskin, F. Z. Ozata, K. Banar, and K. Royle, "Examining digital literacy competences and learning habits of open and distance learners," Contemporary Educational Technology, vol. 6, pp. 74-90, 2015.

[37] P. Nilsook, N. Utakrit, and J. Clayden, "Imagineering in education: A framework to enhance students' learning performance and creativity in thinking," Educational Technology, vol. 54, pp. 14-20, January-Febuary 2014.

[38] J. Kenton and B. Blummer, "Promoting digital literacy skills: Examples from the literature and implications for academic librarians," Community \& Junior College Libraries, vol. 16, pp. 84-99, 2010.

[39] S. Bernsmann and J. Croll, "Lowering the threshold to libraries with social mediathe approach of "digital literacy 2.0," a project funded in the EU Lifelong Learning Programme," Library Review, vol. 62, pp. 53-58, 2013.

[40] Y.-T. C. Yang and W.-C. I. Wu, "Digital storytelling for enhancing student academic achievement, critical thinking, and learning motivation: A year-long experimental study," Computers \& Education, vol. 59, pp. 339-352, September 2012.

[41] L. P. Johan and J. B. Johannes, "New trends in content creation Changing responsibilities for librarians," Libri, vol. 61, pp. 12-22, 2011.

[42] D. McMenemy, "Less conversation, more action: Putting digital content creation at the heart of modern librarianship," Library Review, vol. 56, pp. 537-541, 2007.

[43] B. Chawner, "How to use web 2.0 in your library," The Electronic Library, vol. 26, pp. 427-428, 2008.

[44] S. Owen, P. Hagel, B. Lingham, and D. Tyson. Development of the digital literacies teaching resource. [Online]. (2013). Available: http://www.deakin.edu.au/_data/assets/pdf_file/0017/38006/digital-li teracy.pdf

[45] J. Na-songkhla. (2011). No boundaries of Learning: An OpenLearn system at Chulalongkorn University. [Online]. Available: http://www.editlib.org/p/37380

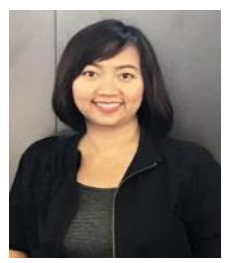

Siriwatchana Kaeophanuek was born in Yala province, Thailand, on September 6, 1980. She is a Ph.D. candidate in the Department of Educational Technology and Communication, Faculty of Education, Chulalongkorn University, Thailand, a master of science degree program in management information technology, Walailak University, Thailand in 2007 and the bachelor degree in information studies, Walailak University, Thailand in 2002. She worked at the School of Informatics, Walailak University, Nakhon Si Thammarat, Thailand from 2007 to present. Ms. Kaeophanuek's research focus on knowledge management, digital literacy, instructional design, social media tools for teaching, online engagement and learning.

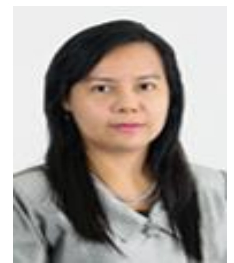

Jaitip Na-songkhla is an associate Professor at the Department head of Educational Technology and Communication, Faculty of Education Chulalongkorn University. For educational background is a $\mathrm{PhD}$ from Leadership in Educational Policies studies (Instructional Technology), Northern Illinois University, U.S.A.

Assoc. Prof. Na-songkhla expertise is in the area of digital and mobile Learning Technology as well as technology in organization that includes approaches in Performance Technology and Knowledge Management. Her academic contribution in Career / Professional Development is continually to school teachers and faculty development. Her published books and articles are in a spectrum of E-learning, Web Collaborative Learning, Performance \& Technology, Social Media, Distance/Flexible Learning, and Virtual Learning Environment.

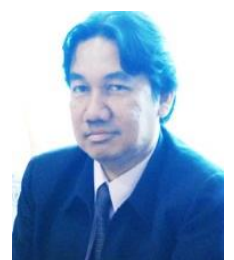

Prachyanun Nilsook was born in Phetchaburi province, Thailand, on June 1, 1965. For educational background is a $\mathrm{PhD}$ from the educational communications and technology, Chulalangkorn University, Bangkok, Thailand in 2001, the master degree in educational technology, Srinakarinwirot University Prasarnmitra, Bangkok in 1995 and the bachelor degree in audio-visual education, University, Bangkok in 1989.

$\mathrm{He}$ is an associate Professor at the information and communication technology for education, Faculty of Technical Education, King Mongkut's University of Technology North Bangkok (KMUTNB), Thailand. He is a member of Professional Societies in the Association for Educational Technology of Thailand (AETT).

Assoc. Prof. Nilsook research topics and interests include instructional design, e-learning, e-training, ICT management, ICT in education, knowledge management in higher education, human performance technology and imagineering. 